\title{
Adult Mammalian Sensory and Motor Neurons: Roles of Endogenous Neurotrophins and Rescue by Exogenous Neurotrophins after Axotomy
}

\author{
John B. Munson, ${ }^{3}$ David L. Shelton, ${ }^{2}$ and Stephen B. McMahon ${ }^{1}$ \\ 'Department of Physiology, St Thomas' Hospital Medical School, London SE1 7EH, United Kingdom, '2Department of \\ Neuroscience, Genentech Inc., South San Francisco, California 94080, and ${ }^{3}$ Department of Neuroscience, University of \\ Florida College of Medicine, Gainesville, Florida 32610
}

\begin{abstract}
We have tested the ability of neurotrophins to reverse axotomyinduced changes in adult motor and sensory neurons, using the physiological measure of conduction velocity. Five weeks after axotomy, sensory and motor conduction velocities were greatly reduced. NT-3 at $60 \mu \mathrm{g} / \mathrm{d}$, pumped directly onto the cut nerve stump, largely prevented the change in sensory fibers. Lower doses were less effective, and NT-4/5 was without effect. In contrast, both NT-3 and NT-4/5 were effective at rescuing motoneurons, with similar dose dependencies. This amelioration of physiological deficits in adult mammalian neurons suggests possible therapeutic application of neurotrophins. We
\end{abstract}

have also studied the physiological effects of neurotrophin deprivation on intact peripheral neurons. After 2 weeks of sequestration of trkB ligands (BDNF and NT-4/5), motor, but not sensory, neuron conduction was significantly slowed. Sequestration of NT-3 was found to affect both motor and sensory fiber velocities but more modestly and only with higher doses of sequestering agent. These data therefore suggest that peripherally produced neurotrophins are necessary for the maintenance of normal functional properties of peripheral neurons.

Key words: axotomy; motoneurons; sensory neurons; degeneration; neuropathy; neurotrophin; NT-3; NT-4/5
During development, all branches of the peripheral nervous system (sensory, motor, and autonomic) depend critically on the availability of neurotrophins (Barbacid, 1994; McMahon and Priestley, 1995). Little is known, however, about the role of neurotrophins in adult animals, even though most neurons of the peripheral nervous system continue to express one or more of the trk receptors (see McMahon and Priestley, 1995). The patterns of trk expression continue to be specific. Thus, small sensory neurons mostly express trkA, whereas trkC is expressed predominantly in large sensory neurons. Most spinal motoneurons express trkB and many also express trkC, but not trkA (Henderson et al., 1993).

There is good evidence that target-derived NGF exerts physiological effects on small sensory neurons in the mature animal (McMahon et al., 1995). There is also circumstantial evidence for other neurotrophins. First, these continue to be expressed in peripheral targets in adult animals (Funakoshi et al., 1993; Koliatsos et al., 1993; Griesbeck et al., 1995). Second, motoneurons and large sensory neurons show dramatic changes in their properties after axotomy of their peripheral axons, when the retrograde supply of target-derived factors is compromised. These changes include (1) a drop in neurotransmitter levels; (2) a series of electrophysiological alterations [decline in axonal conduction velocity (CV), rheobase, EPSP amplitude, and duration of afterhyperpolarization and increase of input resistance for motoneu-

\footnotetext{
Received July 26, 1996; revised Sept. 27, 1996; accepted Oct. 17, 1996.

This work was supported by grants from the Medical Research Council of Great Britain (S.B.M.), National Institutes of Health Grant RO1 NS-15913 (J.B.M.), and a Collaborative Research Grant from NATO. We thank Caroline Abel, Tabitha Springall, Cathleen Yedinak, Dr. Sridhar Viswanathan, and Dr. Charles Schmelzer for their excellent technical assistance.

Correspondence should be addressed to Prof. S. B. McMahon, Department of Physiology, St. Thomas Hospital Medical School, Lambeth Palace Road, London SE1 7EH, UK.

Copyright (C) 1996 Society for Neuroscience $0270-6474 / 96 / 170470-07 \$ 05.00 / 0$
}

rons; reduced $\mathrm{CV}$ and inability to generate synaptic potentials for sensory neurons]; (3) ultimately, the death of many axotomized neurons. Because most of these changes are reversed or prevented if sensory and motor neurons regenerate back to peripheral targets (Mendell et al., 1995), it seems likely that they are dependent on target-derived factor(s). This conclusion is supported also by the fact that several of the effects of axotomy are seen in intact neurons treated with axonal transport blockers to their peripheral axons (Csillik and Knyihar-Csillik, 1982; Fitzgerald et al., 1984) or blockage of neuromuscular transmission (Pinter et al., 1991).

The aims of the present study were twofold: (1) to test the hypothesis that provision of exogenous neurotrophins to axotomized myelinated sensory and motor neurons will reverse physiological effects of axotomy, and (2) to test the hypothesis that sequestration of trkB and trkC ligands will result in axotomy-like physiological effects on sensory and motor neurons. As model systems, we have chosen hindlimb nerves of the rat, which contain both motor and sensory neurons. Provision or deprivation of specific neurotrophins to these mixed nerves permits us to test their effectiveness on both motor and sensory neurons. Rather than explore the entire range of physiological effects of axotomy, which would require low-yield intracellular techniques, we have chosen instead to use axonal CV of sensory and motor neurons (measured by stimulating peripherally and recording from dorsal or ventral roots) as being representative of the spectrum of effects of axotomy. This is justified by the fact that the various electrophysiological effects of axotomy and of recovery from axotomy are known to occur in concert (Foehring et al., 1986).

\section{MATERIALS AND METHODS}

We performed experiments on 64 adult male Wistar rats (tibial nerve experiments, $n=41$; gastrocnemius nerve experiments, $n=23$; see below), mean weight $271 \pm 6$ (SE) gm. Animals were prepared in an 
A
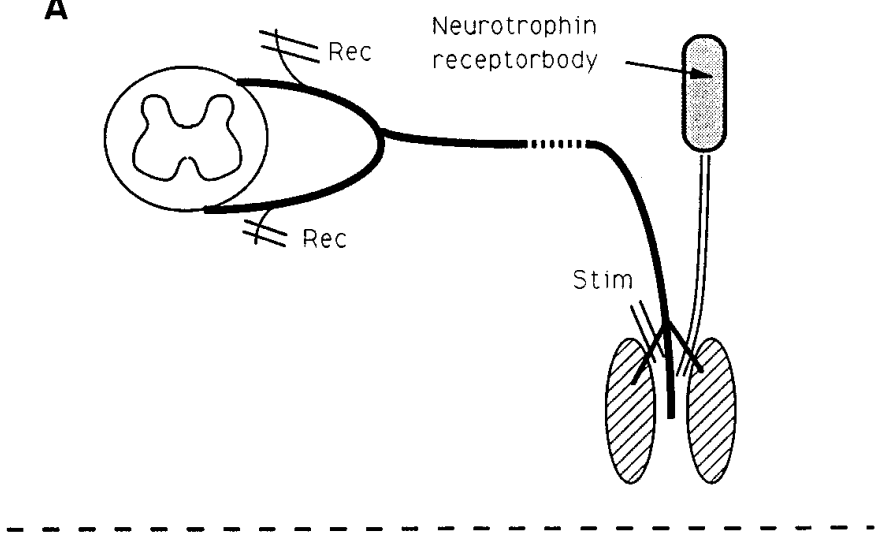

B

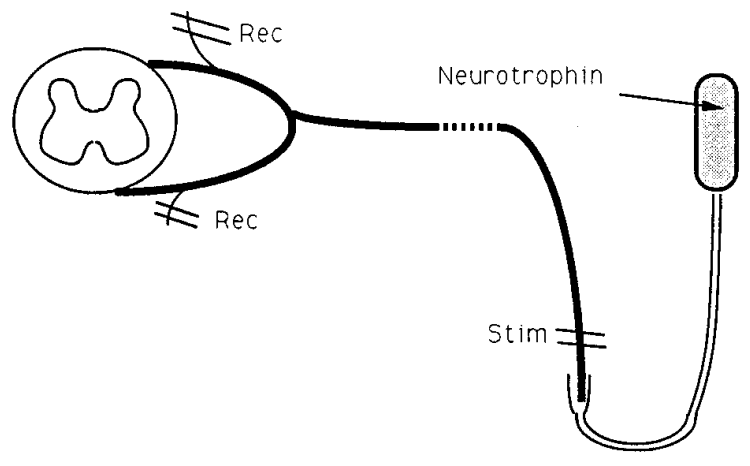

C STIM

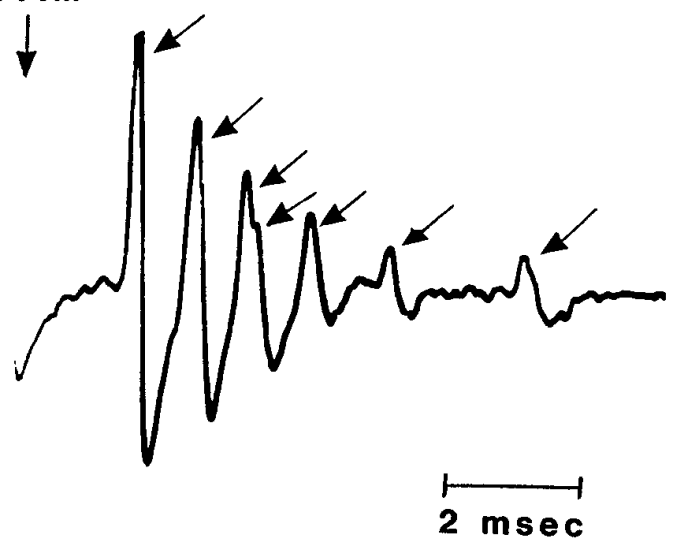

D

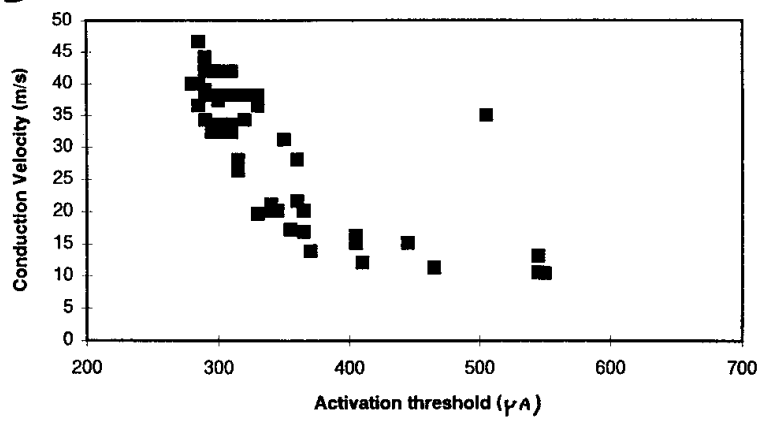

Figure 1. Experimental procedures. $A$, To test the effect of sequestration of specific neurotrophins on motor and sensory neurons, trkB-IgG and/or trkC-IgG was perfused between the heads of the gastrocnemius muscles. Action potentials were elicited by stimulation of the gastrocnemius muscle nerves and recorded in dorsal (sensory) and ventral (motor) root neurons to determine CV. B, To test the ability of neurotrophins to rescue CV of axotomized motor and sensory neurons, the tibial nerve was axotomized and provided with exogenous neurotrophins by miniosmotic pump and silicone tubing. CVs of tibial sensory and motor neurons were measured as above. $C$, Action potentials of individual fibers (arrows) were recorded from a multifiber dorsal root strand. Smaller, later-arriving action potentials require progressively greater stimulus currents than do larger, early-arriving action potential. $D$, Scattergram of latency (inversely related to CV) and current threshold of normal sensory neurons. Neurons recruited by current spread to other nerves would be of short latency but high threshold (e.g., the data point at $500 \mu \mathrm{A}, 35 \mathrm{~m} / \mathrm{sec}$ ).

initial procedure using pentobarbitone anesthesia, $40 \mathrm{mg} / \mathrm{kg}$, intraperitoneally, and with sterile precautions. Animals tolerated all procedures without incident, gained weight normally, and appeared in excellent health throughout the procedures.

Preparatory procedures. We conducted experiments of two types: effects of NT-receptor bodies (trkB- $\mathrm{IgG}$ and trkC-IgG) on intact nerves and effects of exogenous NT-3 and NT-4/5 on axotomized nerves. Effects of these molecules on peripheral nerve $\mathrm{CV}$ were determined by comparison with CVs of normal untreated nerves and with CV of axotomized nerves, cut and capped with a $5 \mathrm{~mm}$-long, $1 \mathrm{~mm}$ diameter blind sleeve of Gore-Tex, (W.L. Gore). The data consist of CVs of normal, normal and trkIgG-treated, axotomized, and axotomized and NT-treated single tibial or gastrocnemius nerve fibers. CVs were measured from the periphery to dorsal (sensory) and ventral (motor) roots.

To investigate the effects of sequestering NTs, we infused NT receptor bodies in the form of trkB-IgG and/or trkC-IgG molecules (Shelton et al., 1995) into the region of the gastrocnemius muscles. A silicone tube led from a subcutaneously implanted miniosmotic pump (Alzet type 2002) to the space between the heads of gastrocnemius medialis and lateralis and delivered the trk-IgGs at 12 or $60 \mu \mathrm{g} / \mathrm{d}$. Effects on gastrocnemius sensory and motor nerve CVs were tested after 2 weeks treatment.

To investigate the ability of exogenous NTs to ameliorate physiological effects of axotomy (as an experimental model of mammalian peripheral neuropathy), we used the axotomized tibial nerve. The tibial nerve is a readily accessible mixed nerve containing both motor and sensory axons projecting in large numbers through spinal roots L4-L6. The central stump of the cut tibial nerve was placed in a $10 \mathrm{~mm}$ Gore-Tex sleeve that had been secured with cyanoacrylate to a 25 -mm-long silicone tube containing a stylette. The tube was directed centrally, and the skin closed over it. One or 3 weeks later, the tube was reexposed, the stylette withdrawn, and a miniosmotic pump (Alzet type 2002) containing NT or vehicle (10 mm acetate, $140 \mathrm{~mm} \mathrm{NaCl}, \mathrm{pH} 4-5)$ attached.

Experimental procedures. Terminal acute experiments were performed using urethane anesthesia $(1.25 \mathrm{~g} / \mathrm{kg}$, i.p. $)$. The trachea and a carotid artery were cannulated, the spinal cord exposed by L2-L5 dorsal laminectomy, and paraffin oil pools created over the exposed spinal cord and the popliteal fossa of the left hindlimb. Core body temperature was maintained near $37^{\circ} \mathrm{C}$. Fine multifiber strands were dissected in turn from the centrally cut dorsal and ventral roots of L4 and L5 and placed on silver electrodes for recording action potentials elicited by electrical stimulation of the tibial or gastrocnemius nerves (Fig. $1 A$ ). As stimulating current was progressively increased, the latency and current threshold were noted as each fiber was recruited (typically four to seven per strand) (Fig. 1C). Scattergrams of these values (Fig. 1D) were inspected to eliminate fibers that might have been recruited from the intact sural or common peroneal branches of the sciatic nerve (i.e., any with short latency but high threshold). Fifty to 100 each sensory and motor fibers were sampled in each experiment. After data collection, animals were killed by anesthetic overdose, and nerve conduction distance was measured for calculation of CV. Pumps were inspected to confirm that they had expelled their contents, and the integrity and placement of tubes and connections were confirmed.

Data analysis. The entire distributions of CVs were plotted as cumulative sum (cusum) histograms. Cusums from individual animals in each group $(n=3-5)$ were averaged. The distributions from different experimental groups were compared statistically using the KolmogorovSmirnov test. Additionally, the CV of the fastest $10 \%$ of sensory and 
motor axons from each animal were computed. Mean and SE of each treatment group were then generated and tested statistically with Student's $t$ test. No allowance was made for utilization time in calculating CV from latency.

\section{RESULTS}

In all experimental and control animals, CVs of 50-100 sensory axons and 50-100 motor axons were determined by recording from filaments of the L4 and L5 dorsal and ventral roots, respectively, while electrically stimulating the tibial or gastrocnemius nerves peripherally (Figure $1, A$ and $B$ ). For each animal, it was therefore possible to reconstruct the CV distribution of both sensory and motor neurons. The CV distribution of the three to six animals in each treatment group was then averaged.

\section{CV of normal and axotomized sensory and motor neurons}

In intact animals CVs of myelinated sensory axons are distributed rather uniformly from about 10 to $55 \mathrm{~m} / \mathrm{sec}$. Normal motor axons have a bimodal $\mathrm{CV}$ distribution with one peak corresponding to $\gamma$ motoneurons, conducting at $\sim 10-30 \mathrm{~m} / \mathrm{sec}$, and a second peak corresponding to $\alpha$ motoneurons, conducting at $\sim 30-55 \mathrm{~m} / \mathrm{sec}$. These distributions are easily appreciated in cusum histograms of the entire obtained populations of mean $\mathrm{CVs}$ for each treatment group (Fig. $2 A, B$, respectively).

Both sensory and motor axons showed progressive slowing 1, 3, and 5 weeks after axotomy (Fig. 2), and these changes are significant already by 1 week $(p<0.05$ in all cases vs intact fibers, Kolmogorov-Smirnov test). Although all fiber sizes appear to be affected, the shift in CV is seen most reliably in the larger fibers. This is likely attributable to the fact that the smaller fibers, having higher thresholds of activation and greater susceptibility to damage during dissection, are subject to more experimental variability and therefore may be under-represented in some experiments. The fastest $10 \%$ of sensory and motor fibers are easily activated, detected, and measured, and give a reliable indication of the condition of a group of fibers reproducible from one treatment to another. We have therefore analyzed and present also the mean CVs of the fastest-conducting $10 \%$ of fibers from each animal of each treatment group (see Figs. 4, 5). By this measure, mean sensory axon CV drops from $49 \mathrm{~m} / \mathrm{sec}$ in intact nerves to 43,40 , and $35 \mathrm{~m} / \mathrm{sec}$ after 1,3 , and 5 weeks, statistically significant at all times ( $p<0.05$ in all cases, Student's $t$ test). For motor axons, the fastest axons conducted at $51 \mathrm{~m} / \mathrm{sec}$ (mean, intact) and fell significantly to 47,44 , and $40 \mathrm{~m} / \mathrm{sec}$ after 1,3 , and 5 weeks of axotomy ( $p<0.05$ in all cases, Student's $t$ test).

\section{Effects of exogenous neurotrophins on axotomized neurons}

In these experiments, tibial nerves were axotomized for 5 weeks. The effects of exogenous neurotrophin treatment for the last 2 or 4 of the 5 weeks were studied. NT-3, NT- $4 / 5$, or a combination of the two was given at total doses of 6 or $60 \mu \mathrm{g} / \mathrm{d}$ (Figs. 3-5). In each animal, both sensory and motor axons were studied.

\section{Sensory neurons}

Two weeks of treatment with NT-3 at $6 \mu \mathrm{g} / \mathrm{d}$ after 3 weeks' axotomy was without significant effect on $\mathrm{CV}$ of sensory fibers (i.e., CVs did not differ from the 5 week axotomy values) (Figs. $3 A$, 4). However, the same treatment with NT-3 at $60 \mu \mathrm{g} / \mathrm{d}$ retained sensory $\mathrm{CVs}$ at values intermediate between those of normal and of 5 weeks' axotomy, a value that was close to that existing at the time of onset of NT treatment (i.e., after 3 weeks of
A

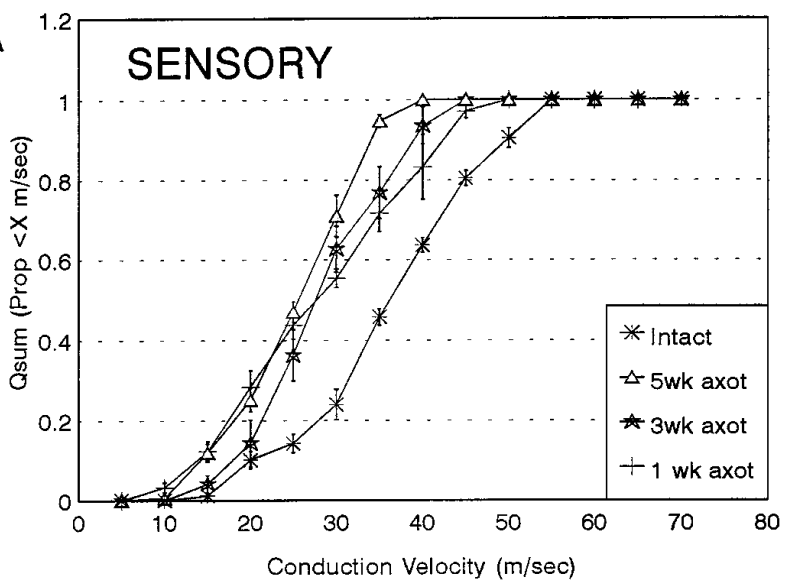

$B$

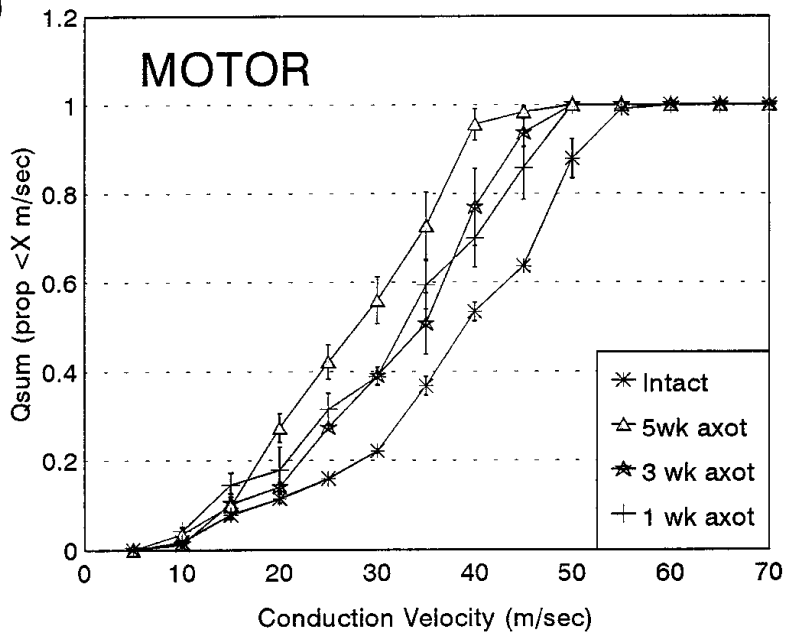

Figure 2. Cusum histograms of CVs of normal and axotomized sensory $(A)$ and motor $(B)$ neurons. Values ( \pm SEM) are each from three experiments. Axotomy progressively slows CVs of both populations, indicated by progression of distributions to the left (lower values). Decline of CVs is evident particularly in the faster portions of each sample. Accordingly, the fastest $10 \%$ of each of these populations is shown in Figures 4 and 5.

axotomy) (Figs. 3B, 4). The distribution of CVs was significantly different from the vehicle-treated group ( $p<0.01$, KolmogorovSmirnov test), as was the value of the fastest $10 \%$ of fibers $(p<$ 0.01: Student's $t$ test). Even greater rescue of CV occurred with 4 weeks of NT-3 treatment at this dose (Figs. 3C, 4); CVs were equal to or higher at the end of the treatment than at the 1 week time of axotomy. With this treatment, the distribution of $\mathrm{CV}$ was not significantly different from that of intact animals $(p<0.05$, Kolmogorov-Smirnov test).

NT-4/5 alone at any dose was without effect on the fastest $10 \%$ of sensory axon CVs (Fig. 4), but at the highest dose had a small, nonsignificant effect on the overall distribution of CVs (Fig. 3C). Combinations of NT-3 and NT-4/5 at high dose were no more effective than NT-3 alone, consistent with the lack of effect of NT-4/5 alone. 


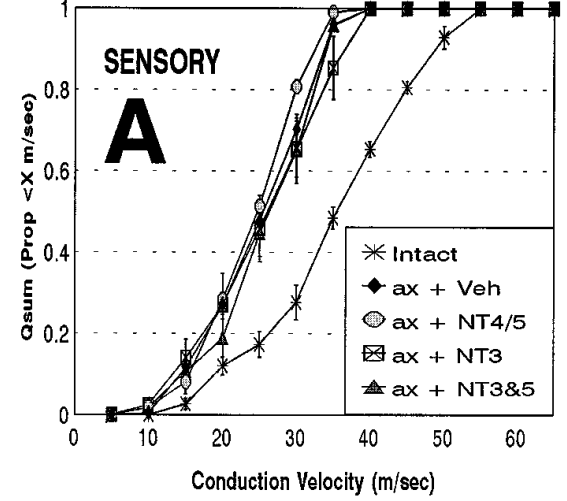

5 week axotomy/ 2 week NT ( $6 \mu \mathrm{g} /$ day)

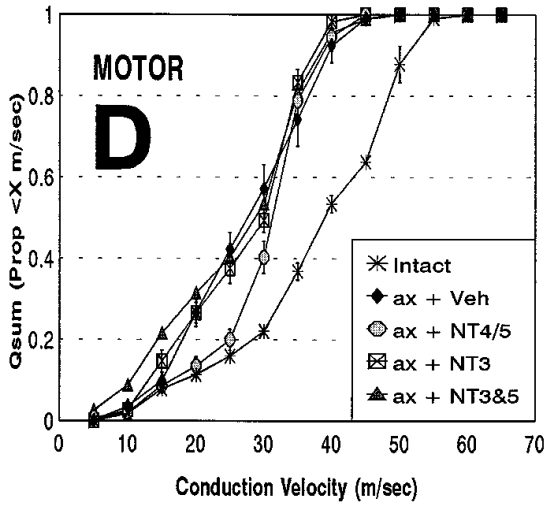

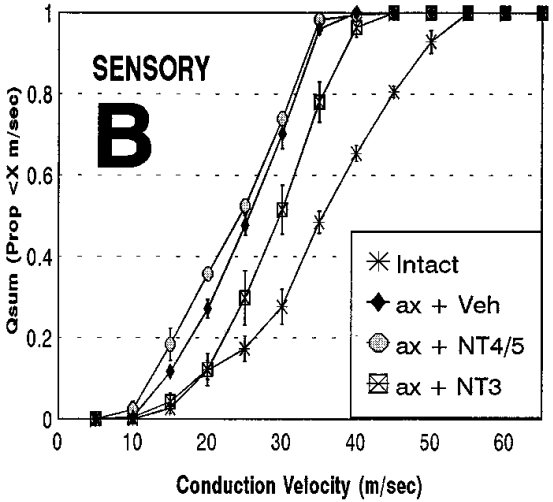

5 week axotomy/ 2 week NT ( $60 \mu \mathrm{g} /$ day $)$

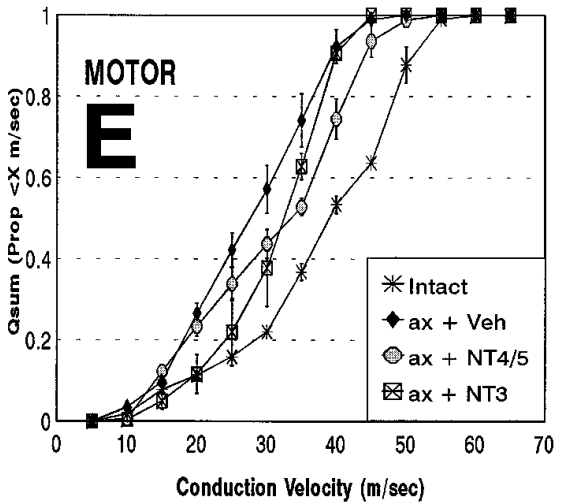

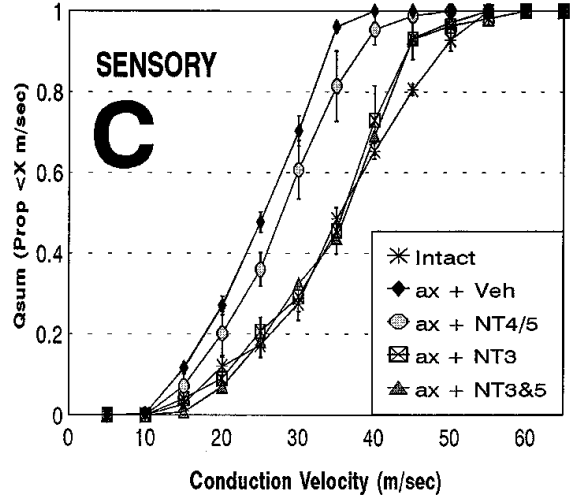

5 week axotomy/ 4 week NT $(60 \mu \mathrm{g} /$ day $)$

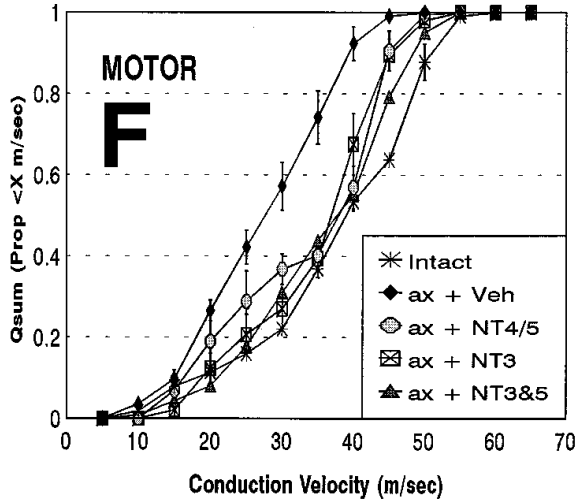

Figure 3. Cusum histograms of CVs of normal and axotomized and treated (vehicle or neurotrophin) tibial nerve sensory and motor axons. Data points $( \pm$ SEM) are averages from three experiments. CVs of sensory axons were rescued by higher doses of NT-3; CVs of motor axons were rescued by higher doses of both NT-3 and NT-4/5.

\section{Motoneurons}

Treatment of axotomized motor nerves with neurotrophins at 6 $\mu \mathrm{g} / \mathrm{d}$ was largely without effect on motoneuron $\mathrm{CV}$. The were no significant changes in the fastest $10 \%$ of fibers $(p>0.05$, Student's $t$ test) (Fig. 5) or in the cusum distributions for NT-3 (Fig. $3 D$ ). However, the low-dose NT-4/5 treatment group was significantly different from the vehicle-treated animals, with the difference consisting of a small shift in only the more variably sampled slowly conducting fibers. The higher doses of neurotrophin, however, had robust and consistent effects. Treatment for 2 weeks with NT-4/5 at $60 \mu \mathrm{g} / \mathrm{d}$ produced a clear and highly significant shift in the $\mathrm{CV}$ distribution $(p<0.01$, Kolmogorov-Smirnov test). When NT-4/5 was given for 4 weeks at this higher dose, there was an additional rightward shift in the overall $\mathrm{CV}$ distribution (Fig. $3 F$ ), although the fastest $10 \%$ of motor axons showed no additional improvement (Fig. 5) ( $p>0.05$; Student's $t$ test).

Motor axons were sensitive also to treatment with NT-3 at the higher dose; both 2 and 4 weeks at $60 \mu \mathrm{g} / \mathrm{d}$ resulted in significant shifts in the CV distribution $(p<0.05$, Kolmogorov-Smirnov test). Only the 4 week treatment, however, had a significant effect on the fastest axons $(p<0.05$, Kolmogorov-Smirnov test). The combined treatment NT-3 and NT-4/5 at the higher dose (Fig. 5) showed no significant improvement over that of the individual neurotrophins.

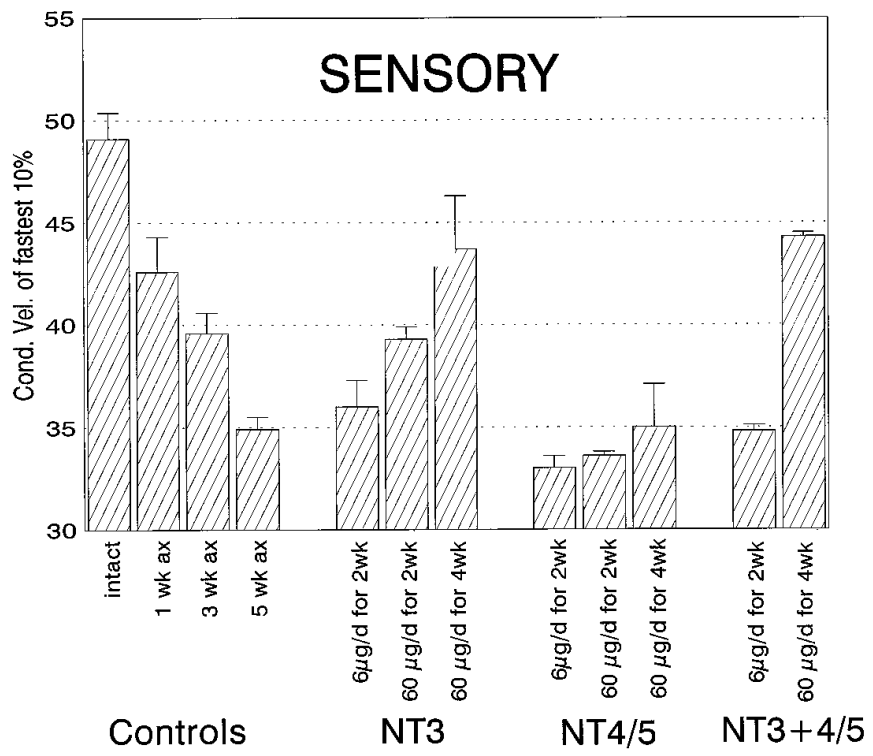

Figure 4. Histograms of CVs of fastest $10 \%$ of normal, axotomized, and axotomized and NT-treated tibial nerve sensory neurons. Data ( \pm SEM) are averages from three experiments. Neurotrophins were provided for the last 2 or 4 weeks of the 5 week axotomy period. NT-3 at higher doses, but not NT-4/5, rescued sensory neurons from additional loss of CV. 


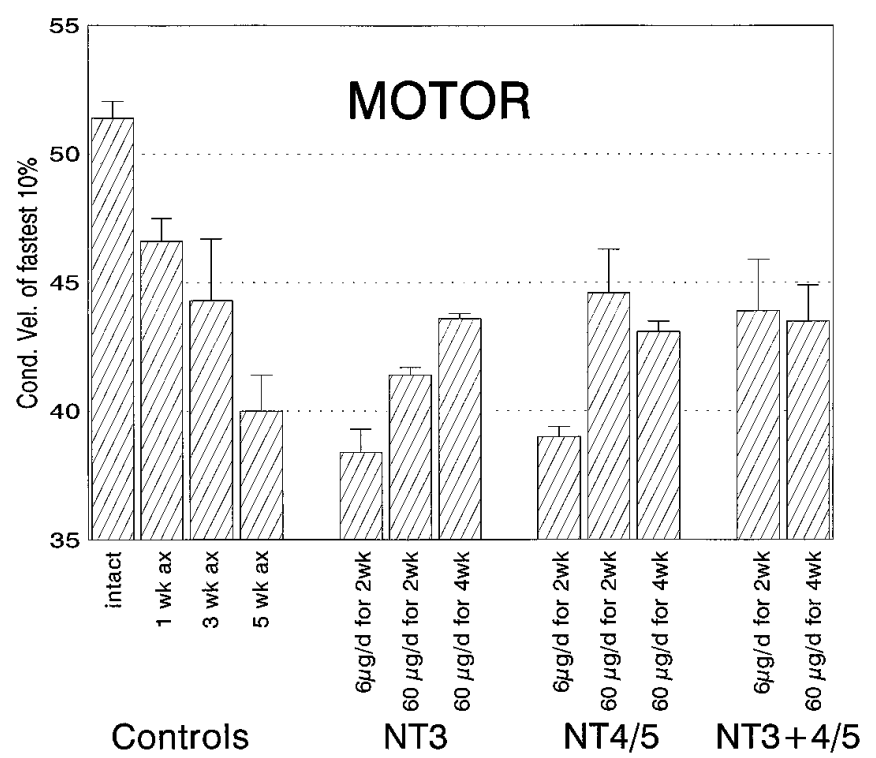

Figure 5. Histograms of CVs of fastest $10 \%$ of normal, axotomized, and axotomized and treated tibial nerve motor neurons. Data $( \pm$ SEM) are averages from three experiments. Neurotrophins were provided for the last 2 or 4 weeks of the 5 week axotomy period. Both NT-3 and NT-4/5 effected rescue of motoneuron CV. Note that 4 weeks of NT-4/5 treatment was no more effective than 2 weeks of treatment.

\section{Effects of sequestration of endogenous neurotrophins on intact neurons}

We also tested the effects of sequestration of specific ligands on $\mathrm{CV}$ of intact sensory and motor neurons. trkB-IgG and/or trkC$\mathrm{IgG}$ was infused for 2 weeks into the gastrocnemius muscles, and measurement was made of CVs of the gastrocnemius sensory and motor neurons. Control animals receiving identical surgery but delivery of only vehicle showed no significant changes in sensory or motor CV (data not shown).

\section{Motoneurons}

Two weeks' treatment with trkB-IgG (Fig. $6 D$ ) at $12 \mu \mathrm{g} / \mathrm{d}$ significantly reduced $\mathrm{CV}$ of intact gastrocnemius motor axons $(p<0.01$, Kolmogorov-Smirnov test) (Fig. 6D). After this treatment, CVs were intermediate between those of intact and 2 week axotomized motoneurons. The effect was specific to motoneurons (see below) accounting for any uncontrolled experimental variables. Treatment with the same dose of trkC-IgG was without significant effect (Fig. $6 E)$, but a fivefold higher dose $(60 \mu \mathrm{g} / \mathrm{d})$ resulted in a significant slowing ( $p<0.01$, Kolmogorov-Smirnov test) (Fig. $6 F$ ) that was somewhat smaller than that seen with trkB-IgG. Combined treatment with trkB-IgG and trkC-IgG at $12 \mu \mathrm{g} / \mathrm{d}$ was no more effective than trkB-IgG alone (data not shown).

\section{Sensory neurons}

At $12 \mu \mathrm{g} / \mathrm{d}$, neither trkB-IgG nor trkC-IgG reduced $\mathrm{CV}$ of gastrocnemius sensory neurons (Fig. $6 A, B$ ). Similarly, combined treatment with trkB-IgG and trkC-IgG at this dose produced no significant reduction in $\mathrm{CV}$ (data not shown). However, treatment with trkC-IgG at $60 \mu \mathrm{g} / \mathrm{d}$ did result in a significant reduction in CV ( $p<0.05$, Kolmogorov-Smirnov test) (Fig. 6C), which appeared more marked on the fastest conducting fibers.

\section{DISCUSSION}

The principal findings of this study are (1) that at least one functional consequence of peripheral axotomy of motor and sen- sory neurons can be reversed by provision of specific exogenous neurotrophins, and (2) that in adult animals with intact peripheral nerves, deprivation of specific neurotrophins can produce an axotomy-like effect. The latter finding implies that neurotrophins continue to exert physiological effects on peripheral neurons in adult animals, whereas the former suggests a potential therapeutic role in the treatment of some peripheral neuropathies.

\section{Provision of exogenous neurotrophins to axotomized peripheral nerves \\ Motoneurons}

On motoneurons, we observed that exogenous NT-4/5 and, to a lesser extent, NT-3, were able to rescue cells from an effect of axotomy. These results are consistent with the known patterns of trk expression in adult motoneurons. In one study, $96 \%$ of adult motoneurons projecting through the sciatic nerve were found to express trkB and $82 \%$ trkC (Henderson et al., 1993). It is not clear whether the two major subgroups of motoneurons, $\alpha$ and $\gamma$, differentially express trks. In the present study, we can distinguish between these neurons on the basis of $\mathrm{CV}$; the break point between the groups lies at $\sim 25-30 \mathrm{~m} / \mathrm{sec}$. It is interesting that the trend in our data was for NT-3 to be more effective on the slower motoneurons and the NT-4/5 on the faster motoneurons, at least with the higher dose of neurotrophin used (see Fig. 3). If substantiated, this would suggest that the entire innervation of muscle spindles ( $\gamma$ motoneurons and large sensory neurons) is sensitive selectively to NT-3, and this in turn is consistent with the preferential expression of NT-3 mRNA in muscle spindles (Copray and Brouwer, 1994). Groups Ia and Ib sensory fibers, fusimotor neurons, and intrafusal muscle fibers are all absent in NT-3-deficient mice (Ernfors et al., 1994; Kucera et al., 1995). A preferential effect of NT-4/5 to rescue $\alpha$ motoneurons is consistent also with the distribution of trkB ligands in extrafusal muscle fibers (Koliatsos et al., 1993; Funakoshi et al., 1993; Griesbeck et al., 1995). It is also possible that some of these observed effects of NT-3 may have been mediated by its ability to signal via trkB.

Our findings here are consistent with a histochemical study by Friedman et al. (1995), who reported that BDNF and NT-4/5 applied to tibial motoneurons could reverse the downregulation of ChAT that occurred with axotomy. They too found that relatively high doses of neurotrophin were necessary (30 but not $3 \mu \mathrm{g} / \mathrm{d}$ ).

\section{Sensory neurons}

Axotomized myelinated sensory neurons were rescued by NT-3. This finding is consistent with the known distribution of trk receptors in adult animals in that many large muscle and cutaneous afferents (the targets of the tibial nerve studied here) are known to express trkC (McMahon et al., 1994). It is also known that many large sensory neurons, particularly those innervating skeletal muscle, are developmentally sensitive to NT-3 (Ernfors et al., 1994; Airaksinen et al., 1996) (see also Snider and SilosSantiago, 1996). The selectivity of action observed here was marked. The trkB ligand NT4/5 was found not to rescue axotomized afferents (at least the faster conducting myelinated population studied here), although some sensory neurons do express trkB in adult animals, and sensory neurons can retrogradely transport NT-4/5 (Curtis et al., 1995).

Our findings with NT-3 on axotomized sensory neurons are consistent with one other report on the neuroprotective action of this molecule in a model of sensory neuropathy. Gao et al. (1995) used repeated systemic injections of NT-3 in animals rendered neuropathic with cisplatin. They monitored H-reflexes to gain an 

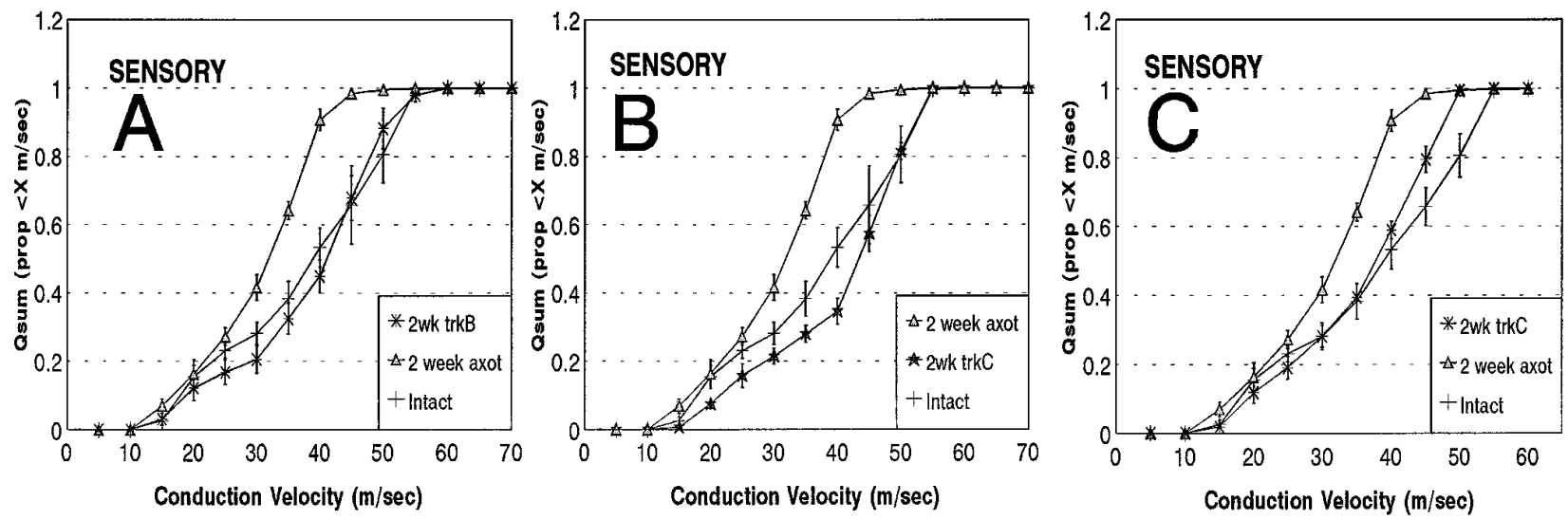

2 week trkB $-12 \mu \mathrm{g} /$ day
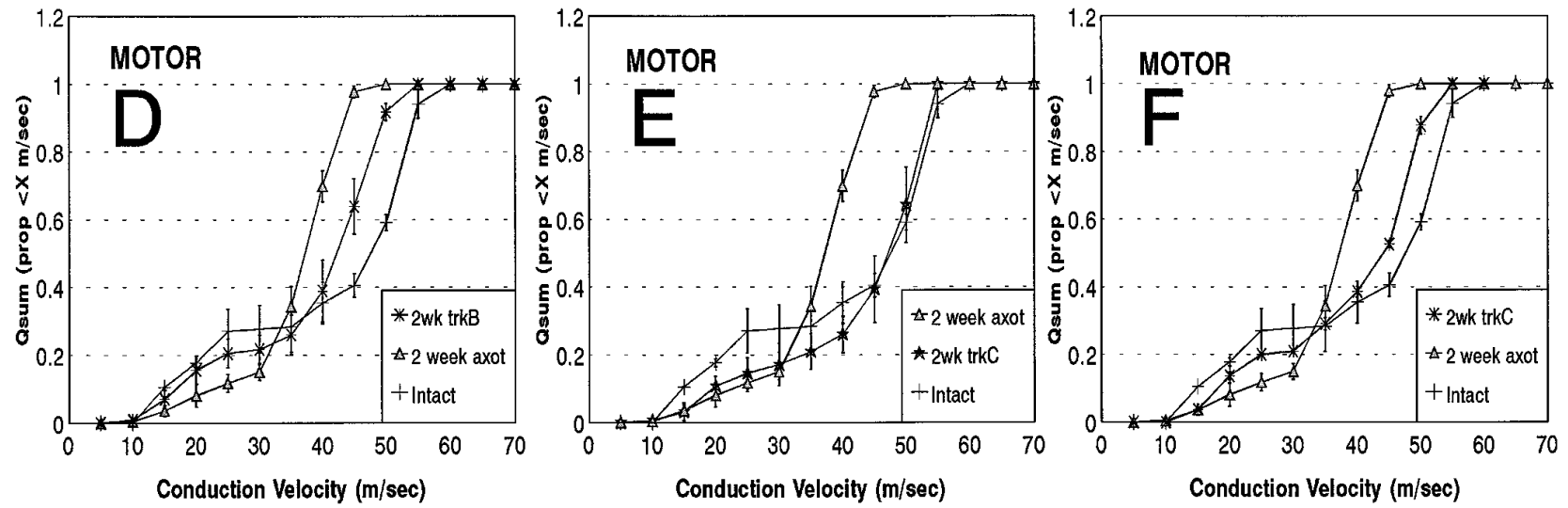

Figure 6. Cusum histograms of CVs of normal and 2 week axotomized gastrocnemius sensory and motor neurons and normal neurons with neurotrophins sequestered by trkB-IgG or trkC-IgG. CVs of motoneurons but not sensory neurons were slowed by trkB-IgG. $\operatorname{trkC}-\operatorname{IgG}$ at $12 \mu \mathrm{g} / \mathrm{d}$ was without effect, but at $60 \mu \mathrm{g} / \mathrm{d}$ both sensory and motor neurons were slowed.

average measurement of the $\mathrm{CV}$ of the fastest muscle afferents. They found that NT-3 at $1 \mathrm{mg} / \mathrm{kg}$, three times per week, was able to prevent cisplatin-induced sensory neuron slowing.

\section{Deprivation of endogenous neurotrophins from intact peripheral nerves}

\section{Motoneurons}

Our experiments with neurotrophin-sequestering molecules also suggest that endogenously produced neurotrophins are important for the normal maintenance of motoneurons. We found that a 2 week period of trkB ligand deprivation was sufficient to induce a consistent and significant slowing of motoneuron CV. Smaller but significant effects were also seen with higher doses of the NT-3-sequestering fusion molecule. In both cases, effects were less than those seen after axotomy, but of course the lesion caused by axotomy is immediate and complete, whereas the trk-IgG treatment is likely to be progressive. It is also possible that access of the trkIgG might be variable, depending on the relative position of cannula and motor nerve terminal. Some motor axons terminating deep within the muscle might lie too far away from the source of sequestering molecule to receive an effective blocking dose. The effects of the trk-IgG fusion molecules are consistent with the rescue effects seen with exogenous neurotrophins. The greater effectiveness of trkB-IgG over trkC-IgG may reflect a genuine difference in the biological roles of trkB ligands versus NT-3. It might also derive from more limited diffusion of the trkC fusion protein.

The importance of neurotrophins on developing motoneurons is presently somewhat uncertain. Animals with "double knockouts" of the BDNF and NT4/5 genes show no significant loss of spinal motoneurons (Conover et al., 1995; Liu et al., 1995), although the initial reports of the trkB knock-out suggested some cell loss here. trkC $(-/-)$ animals are also reported to show a $28 \%$ loss of fibers in ventral roots, implying a limited degree of motoneuron death (Klein et al., 1994).

\section{Sensory neurons}

We did not see any physiological impairment of intact muscle afferents with sequestration of trkB ligands under conditions in which motoneurons were affected. This finding was consistent with the lack of rescue of axotomized sensory neurons by NT-4/5. Sequestration of NT-3 with trkC-IgG at $12 \mu \mathrm{g} / \mathrm{d}$ was also ineffective on muscle sensory neurons. The higher dose of $60 \mu \mathrm{g} / \mathrm{d}$ did result in a significant slowing of, in particular, the fastest sensory axons. This higher dose may have been necessary because the terminals of the relevant fibers are located deeply in the muscle belly and somewhat distant tendons. The actions of trkC-IgG are consistent with the rescue effects of 
NT-3 on damaged sensory axons and with the known patterns of trk expression on these neurons.

The trk immunoadhesins used in this work are quite potent and specific blockers of the neurotrophins, within the limits of their natural ligand specificities. Ligand specificity is most problematic for the experiments using trkB-IgG, because, of the trks, this receptor interacts with the widest range of neurotrophins. BDNF, NT-4/5, and, to a lesser extent, NT-3 all bind to trkB and so might be suspected of being the endogenous molecules being blocked. Although it is impossible to be absolutely certain which ligand(s) is being blocked in the experiments reported here, in vitro work suggests that it is likely that trkB-IgG is primarily working by blocking BDNF and/or NT-4/5. Although neither trkB-IgG nor trkC-IgG has any detectable effect on NGF biological activity, in vitro blocking experiments (data not shown) demonstrate that trkB-IgG is able to shift dose-response curves for BDNF or NT-4/5 biological activity by several orders of magnitude. Under similar conditions, trkB-IgG is only able to shift the doseresponse curve for NT-3 by two- to threefold. Conversely, trkC$\mathrm{IgG}$ has no detectable effect on BDNF or NT-4/5 activity, yet is able to inhibit NT-3 activity by several hundredfold. A higher dose of trkC-IgG than trkB-IgG was required to see even moderate effects on motorneuron $\mathrm{CV}$, and so any effect attributable to the lower dose of trkB-IgG must certainly result from blockade of BDNF or NT-4/5. Thus, although trkB-IgG experiments cannot readily distinguish between BDNF and/or NT-4/5 activity, it is very unlikely that the results obtained with trkB-IgG in this study are attributable to blockade of NT-3.

In summary, these results demonstrate that neurotrophins continue to exert specific biological effects on adult mammalian myelinated sensory and motor neurons. Here, we have used CV as a convenient assay of these effects. CV is determined by axon caliber, which in turn is regulated by neurofilament production. Neurofilament production and transport and axonal diameter and $\mathrm{CV}$ are all reduced after peripheral nerve transection (for review, see Verge et al., 1990). Exogenous NGF restores neurofilament mRNA in the subpopulation of axotomized DRG cells with highaffinity NGF receptors (Verge et al., 1990). The present results suggest that peripheral nerve neurofilament mRNA and, thus, axon caliber and $\mathrm{CV}$ are sensitive also to trkB and trkC ligands. It seems likely that neurotrophins may control other neuronal properties, such as chemical phenotype and neuronal connectivity, which are known to depend on target-derived influences in much the same way as CV. It is also known that many of the electrophysiological consequences of axotomy occur in concert with changes in CV (Foehring et al., 1986). Our results would also predict that particular neurotrophins may be of use therapeutically in treating some peripheral neuropathic states.

\section{REFERENCES}

Airaksinen MS, Koltzenburg M, Lewin GR, Masu Y, Helbig C, Wolf E, Brem G, Toyka KV, Thoenen H, Meyer M (1996) Specific sub-types of cutaneous mechanoreceptors require neurotrophin-3 following target innervation. Neuron 16:287-295.

Barbacid M (1994) The trk family of neurotrophin receptors. J Neurobiol 25:1386-1403.

Conover JC, Erickson JT, Katz DM, Bianchi LM, Poueymirou WT, McClain J, Pan L, Helgren M, Ip NY, Boland P, Friedman B, Wiegand S, Vejsada R, Kato AC, DeChiara TM, Yancopoulos GD (1995) Neuronal deficits, not involving motor neurons, in mice lacking BDNF and/or NT4. Nature 375:235-238.

Copray JC, Brouwer N (1994) A selective expression of neurotrophin-3 messenger RNA in muscle spindles of the rat. Neuroscience 63:1125-1135.
Csillik BE, Knyihar-Csillik E (1982) Reversibility of microtubule inhibitor-induced transganglionic degenerative atrophy of central terminals of primary nociceptive neurons. Neuroscience 7:1149-1154.

Curtis R, Adryan KM, Stark JL, Park JS, Compton DL, Weskamp G, Huber LJ, Chao MV, Jaenisch R, Lee K-F, Lindsay RM, DiStefano PS (1995) Differential role of the low affinity neurotrophin receptor $(\mathrm{p} 75)$ in retrograde axonal transport of the neurotrophins. Neuron 14:1201-1211.

Ernfors P, Lee K-F, Kucera J, Jaenisch R (1994) Lack of neurotrophin-3 leads to deficiencies in the peripheral nervous system and loss of limb proprioceptive afferents. Cell 77:503-512.

Fitzgerald M, Woolf CJ, Gibson SJ, Mallaburn PS (1984) Alterations in the structure, function, and chemistry of $\mathrm{C}$ fibres following local application of vinblastine to the sciatic nerve of the rat. J Neurosci 4:430-441.

Foehring RC, Sypert GW, Munson JB (1986) Properties of selfinnervated motor units of medial gastrocnemius of cat. II. Axotomized motoneurons and time course of recovery. J Neurophysiol 55:947-965.

Friedman B, Kleinfeld D, Ip NY, Verge VMK, Moulton R, Boland P, Zlotchenko E, Lindsay RM, Liu L (1995) BDNF and NT-4/5 exert neurotrophic influences on injured adult spinal motor neurons. J Neurosci 15:1044-1056.

Funakoshi H, Frisen J, Barbany G, Timmusk T, Zachrisson O, Verge VM, Persson H (1993) Differential expression of mRNAs for neurotrophins and their receptors after axotomy of the sciatic nerve. $J$ Cell Biol 123:455-465.

Gao W-Q, Dybdal N, Shinsky N, Murnane A, Schmelzer C, Siegel M, Keller G, Hefti F, Phillips H, Winslow JW (1995) Neurotrophin-3 reverses experimental cisplatin-induced peripheral sensory neuropathy. Ann Neurol 38:30-37.

Griesbeck O, Parsadanian ASH, Sendtner M, Thoenen H (1995) Expression of neurotrophins in skeletal muscle: quantitative comparison and significance for motoneuron survival and maintenance of function. J Neurosci Res 42:21-33.

Henderson CE, Camu W, Clement M, Gouin A, Poulsen K, Karihaloo M, Rullomas M, Evans T, McMahon SB, Armanini M, Berkemeier L, Phillips H, Rosenthal A (1993) Neurotrophins promote motor neuron survival and are present in embryonic limb bud. Nature 363:266-270.

Klein R, Silos-Santiago I, Smeyne RJ, Lira S, Brambrilla R, Bryant S, Zhang L, Snider WD, Barbacid M (1994) Disruption of the neurotrophin receptor gene trkC eliminates Ia muscle afferents and results in abnormal movements. Nature 368:249-251.

Koliatsos VE, Clatterbuck RE, Winslow JW, Cayouette MH, Price DL (1993) Evidence that brain-derived neurotrophic factor is a trophic factor for motor neurons in vivo. Neuron 10:359-367.

Kucera J, Ernfors P, Walro J, Jaenisch R (1995) Reduction in the number of spinal motor neurons in neurotrophin-3-deficient mice. Neuroscience 69:321-330.

Liu X, Ernfors P, Wu H, Jaenisch R (1995) Sensory but not motor neuron deficits in mice lacking NT4 and BDNF. Nature 375:238-241.

McMahon SB, Priestley JV (1995) Peripheral neuropathies and neurotrophic factors: animal models and clinical perspectives. Curr Opin Neurobiol 5:616-624.

McMahon SB, Armanini MP, Ling LH, Phillips HS (1994) Expression and co-expression of trk receptors in subpopulations of adult primary sensory neurons projecting to identified peripheral targets. Neuron 12:1161-1171.

McMahon SB, Bennett DLH, Priestley JV, Shelton D (1995) The biological effects of endogenous NGF on adult sensory neurones revealed by a trkA-IgG fusion molecule. Nature Med 1:774-780.

Mendell LM, Taylor JS, Johnson RD, Munson JB (1995) Rescue of motoneuron and muscle afferent function in cats by regeneration into skin. II. Ia-motoneuron synapse. J Neurophysiol 73:662-673.

Pinter MJ, Vanden Noven S, Muccio S, Wallace N (1991) Axotomy-like changes in cat motoneuron electrical properties elicited by botulinum toxin depend on the complete elimination of neuromuscular transmission. J Neurosci 11:657-666.

Shelton DL, Sutherland J, Gripp J, Camerato T, Armanini MP, Phillips HS, Carroll K, Spencer SD, Levinson AD (1995) Human trks: molecular cloning, tissue distribution, and expression of extracellular domain immunoadhesins. J Neurosci 15:477-491.

Snider WD, Silos-Santiago I (1996) Dorsal root ganglion neurons require functional neurotrophin receptors for survival during development. Philos Trans R Soc Lond [B] 351:395-403.

Verge VMK, Tetzlaff W, Bisby MA, Richardson PM (1990) Influence of nerve growth factor on neurofilament gene expression in mature primary sensory neurons. J Neurosci 10:2018-2025. 